\title{
Competency requirements for managerial development in manufacturing, assembly, and/or material processing functions
}

\author{
Clifford S. Barber and Brian C. Tietje \\ College of Business, California Polytechnic State University, San Luis Obispo, \\ California, USA
}

Keywords Competences, Management development, Manufacturing systems, Assembly

Abstract Organizations that include a manufacturing, assembly and/or material processing (MAMP) functions have become increasingly complex, competitive, and dynamic. These organizations demand increased emphasis on recruiting, developing, and retaining management talent to gain a competitive edge. This paper uses a modified Delphi triangulation approach to identify and categorize first-level MAMP management competencies perceived to be important by three critical stakeholder groups - an expert MAMP upper management panel, first-level MAMP managers who have been employed between one to three years, and business management faculty members. The results identify 14 knowledge, skill, and value-based competencies and three higher-order factors as essential components within the MAMP management function. There was considerable consistency in the perceptions of the three groups in evaluating the importance of these competencies, with the exception that first-level managers placed greater importance on technical skills for daily MAMP activities than upper management.

\section{Introduction}

Identifying the requisite competencies for achievement in an occupational field is a critical process in human resource management. Of particular importance is the task of identifying qualities that define effective managers. The general definition for management competency used in this paper is a cluster of related knowledge, skills, and attitudes that affects a major part of one's job (a role or responsibility), that correlates with performance on the job, that can be measured against well-accepted standards, and that can be improved via training and development (Parry, 1996).

Numerous studies have identified relevant managerial competencies, and several have focused on the complexities and ambiguities of managerial work. Research has indicated that the variations in skills, functions and contexts of management roles makes a one-size-fits-all competency profile impractical (Hales, 1986; Hirsh and Bevan, 1988; McKenna, 2002; Whitely, 1989). Accordingly, this paper seeks to distinguish and identify competencies for a specific group of managers who oversee manufacturing, assembly and/or material processing (MAMP) functions. Because MAMP functions are often technical, generic management competencies developed for non-technical fields (e.g. Rausch et al., 2002) may not be sufficient for defining relevant competencies.

Both authors contributed equally, and the names are listed in alphabetical order. 
The technical MAMP supervisor or manager is primarily concerned with planning, organizing, directing, and controlling the activities of engineers, production workers, research and development (R\&D) people, designers, draftsmen, individual contractors, maintenance staff, and other technical and non technical personnel. All of the above-mentioned employees need to be managed to successfully achieve desired goals in $\mathrm{R} \& \mathrm{D}$, product design and development, manufacturing process control, facility maintenance, quality control, and workforce management.

The competencies needed by MAMP managers which differ from general managers are driven primarily by the technical nature of MAMP environments. The MAMP managers of the future require new management technologies, policies, communication skills, manufacturing process expertise, and leadership styles to manage and thrive in the midst of change. According to Badawy (1995), the job of the technical manager in the twenty-first century will clearly be more complex. Rosenbaum (1991) indicates that technical leadership takes a special combination of knowledge about science and technology to acquire respect, knowledge about behavior, and skill to lead. At the heart of these challenges is the universal need for effective and competent managers. As D'Netto and Sohal (1999, p. 160) explain:

Today, a production manager must have technical knowledge relevant to his/her industry, highly developed interpersonal skills, knowledge of advanced manufacturing technology, knowledge of other functional areas within the organization and the ability to accept and guide change. Gone are the days when the production manager could concern himself/herself only with getting the product out. He/she now needs to produce continually changing products on time, more cheaply and with increasingly better quality.

To survive today, companies must produce world-class, quality products and services, design those products to meet the specific customer's needs, and deliver them quickly anywhere in the world at a competitive price (Howardell, 2003). This will require a manufacturing workforce to work as a team, exhibit creativity, respond to customers, continually improve processes, effectively balance their lives and careers, and turn policy into action.

MAMP functions are a key resource of significant importance to corporate profitability and growth. The need for competent managers in these areas cannot be overemphasized. The organization, coordination, direction, allocation, and control of MAMP operations are the fundamental responsibilities of MAMP managers. How well managers perform these tasks will largely determine the firm's survival and growth.

In this paper, we employ a three-step methodology to identify the competencies that define a successful MAMP manager. We first queried a team of upper management MAMP experts to generate a broad list of competencies required by successful first-level MAMP managers. We then refined the list, pre-tested a survey instrument, and administered the survey among three key constituency groups - seasoned corporate MAMP upper management, first-level MAMP management, and business management faculty whose expertise is primarily in the area of manufacturing. Finally, we analyzed the results to reveal the underlying factors and to compare their relative importance, both now and in the future, among the three respondent groups. The factors that emerged and their perceived importance provide a set of competencies that define a successful MAMP manager, and that can be used for recruiting, training, motivating, and developing a management team within a manufacturing organization. 


\section{Research methodology}

An initial list of competencies required by MAMP managers was generated by a panel of experts who were in corporate positions that were directly relevant to the functions of MAMP managers. For this study, criteria that defined expertise for involvement in the Delphi included: upper-level managers of mid to large size organizations that contain a MAMP component; employed for at least five years with their current organization; and availability and willingness to participate in the Delphi exercise. Of the 36 potential panelists who were contacted about the study, 26 were able to participate. These upper-level managers represented firms from a variety of industries, including, but not limited to, aerospace, industrial electronic systems, plumbing products, and semiconductors, and ranged in size from $\$ 4$ million to $\$ 130$ billion in annual revenues.

Typically, the first step in program development is the identification of instructional and educational objectives. Educational objectives are often categorized into three distinct domains - cognitive, affective and psychomotor. Consistent with this framework, a knowledge-skill-value (KSV) structure was used to facilitate the identification of key competencies. The title of knowledge was selected to represent the cognitive domain, value for the affective, and skill for the psychomotor.

The expert panelists were asked to generate a list of at least five knowledge, five skill, and five value competencies required by MAMP managers. This process yielded a total of 265 competencies. The initial list was independently analyzed by two researchers to categorize the items and eliminate duplicates. The refined list of 109 competencies was incorporated into a questionnaire for pre-testing. The questionnaire's format, length, and style were evaluated, and the wording, potential duplication and relevance of each competency were examined by an independent panel of five business faculty members. The test questionnaire was amended with the suggested changes, and the final version consisted of 33 knowledge, 33 skill, and 27 value competencies for evaluation. The revised questionnaire was sent to the expert and faculty panels, as well as a panel of first-level managers in various manufacturing facilities. For convenience purposes, all of the panelists were located in California. The revised questionnaire was presented in a two-part format with a five-point Likert scale rating both the current and future importance of each competency. A total of 26 usable questionnaires were received from the expert panel, 24 from the faculty panel, and 34 from the first-level manager panel.

\section{Analysis}

Due to the large number of individual KSV competencies (93), we subjected them to exploratory factor analysis in an attempt to identify the underlying dimensions as perceived by the participants. A principal components analysis was conducted on each of the categories in an effort to reduce the data into more manageable scales. A total of 14 factors emerged. Alpha reliabilities ranged from 0.61 to 0.86 , with three scales under the customary reference point of 0.70 . The Appendix summarizes the contents of each factor.

A one-way analysis of variance (ANOVA) was used to determine if significant differences occurred between groups (experts, first-level managers and faculty) in their perceived importance of the factors. If a significant $F$-ratio was found, a post hoc comparison, Tukey's HSD test, was applied to determine where significant differences 
exist. Finally, a paired sample $t$-test was performed to compare perceptions of the current versus future importance of the various competencies.

\section{Emergent factors defining a competent MAMP manager}

The 14 factors that emerged - five knowledge factors, five skills factors, and four value factors - are listed in the Appendix and briefly described as follows.

Knowledge scales

KSCALE1: foundational systems. The theme that runs through this set of items is grounded in the basics of mechanical and manufacturing understanding. A group (expert, first-level manager or faculty) that scores a high rating on this scale feels that it is important to understand technical systems and their applications. This scale focuses on the rudimentary underpinnings of manufacturing equipment, processes, and materials.

KSCALE2: competitive strategies. This scale emphasizes the required tools and concepts necessary for staying ahead of the competition. The group that rates these competencies high recognizes the role that information technology plays in customer satisfaction. Using the speed and efficiency of computer technology to design, present and market a quality product is the focus of this scale. A high rating on this scale also identifies a keen understanding of the organizational wide inter-functional relationships that are required for the successful product throughout its life cycle.

KSCALE3: requisite management. This scale includes competencies that center on successful manufacturing system necessities that occasionally are overlooked to the detriment of the organization. The focus is on compliance to standards that enable employees to produce a quality product in a safe, comfortable, well-organized and controlled environment. Knowledge of these concepts would provide a manager with a good foundation in the area of total quality management.

KSCALE4: project management. The common elements in this scale are directed toward the successful completion of a project. Knowledge of planning and scheduling are essential here. The group that rates high on this scale recognizes that the only way to manage a successful project is to understand the constraint areas that might prevent the steady rate of work. A consistent level of quality combined with a steady rate of throughput enables a project to be managed efficiently.

KSCALE5: materials management. High ratings on this scale indicate that the group recognizes the importance of regulating the flow of materials in an organization. Lowering the amount of money tied up in inventory is the theme for this set of knowledge competencies. Additionally, the critical understanding of the following operational measurements is evident in the scale:

- throughput: the rate at which money is generated by the organization through sales;

- inventory: all the money that the organization has invested in purchasing items it intends to sell;

- operating expenses: all the money that the organization spends to turn inventory into throughput.

The significance of computer technology to enable the materials management effort is a common link within the scale. 
Skill scales

SSCALE1: technical analysis. The theme of this scale is implementing the technical skills that are necessary to analyze a situation and institute a remedy. It is essential that the remedy be based on sound technical constructs. A continually growing base of resources can conceivably improve upon the analysis that is developed. The group that rates high on this scale reveals a critical appreciation for the numerous tools and resources that are available when making comprehensive decisions. The skills that make up this scale establish a foundation in the techniques of situational analysis.

SSCALE2: transformational leadership. A high rating on this scale encompasses the importance of leadership skills in the role of an effective manager. The focus is on interpersonal relationships as a critical area in terms of overall organizational effectiveness. The MAMP manager that excels in the skills that make up this scale will recognize that leadership is an evolving discipline that matures by experience and adaptation toward established benchmarks. Transformational leadership requires the gathering of skills to become more sensitive, conscious and proactive toward the transformation of an organization, leading by example.

SSCALE3: diagnostic efficiency. After a problematic situation has been identified by technical analysis, this scale focuses on the applied skills and techniques that diagnose a situation further. A high rating would indicate a significant value has been placed on the applied dimension. The emphasis is in moving from the theoretical toward the actual. The application of the skills that make up this scale could add a dimension of expediency and efficiency in regulating the situation in question.

SSCALE4: workforce development. A group that rates high on this scale identifies the skills that build positive relationships with the workforce as essential. The skill set provides managers with the tools to identify, relate, respect and utilize employees in an effective manner. This scale has added significance in the light of today's organizational recognition of employees being the backbone of the company.

SSCALE5: organizational strategies. The final skill scale emphasizes decision-making skills and their relationship to the organization as a whole. While the focus of the scale is on the decision making process, the inclusion of teamwork and customer awareness provides direction and priority to the process. Since most problems are viewed as a potential crisis in some area of the organization, it is critical to understand that a team effort is usually exponentially better, and the customer's problems should always be looked upon as a potential crisis.

\section{Value scales}

VSCALE1: credibility management. The focus of this scale is on the values that a manager holds that would enhance credibility. A high rating on this scale would indicate that a successful manager must establish a high level of credibility in order to be followed. Mastery of certain skills and knowledge certainly play a role in one's credibility; however, this scale more accurately depicts a manager's character trait of credibility.

VSCALE2: assertive leadership. A high rating score on this scale would indicate that a group recognizes the importance of being able to manage from an assertive position. A successful manager must avoid being manipulated by another's behavior, or be undermined by others false expectations and assumptions. It is critical that the 
assertive leader values and practices the competencies identified in this scale to prevent communications with others from seeming aggressive.

VSCALE3: collaborative management. The focus of this scale is on sensitivity and participation. The collaborative manager cares deeply about others by developing their self worth and self-respect both from a personal and organizational perspective. To avoid being manipulated, the collaborative values must be balanced with the assertive values presented in VSCALE2. A high rating of this scale recognizes a commitment to developing a positive organizational climate through an individual's positive self-image which results in high morale and increased productivity.

VSCALE4: responsiveness management. The focus of this scale is on taking action. A high group rating of this scale indicates the importance of self-directed incentive. A successful manager must value the process of careful listening and understanding the inputs, and the satisfaction of transforming them into outputs without extensive hand-holding or external motivation.

\section{Perceived importance of each factor}

The perceived importance of the competency factors was extremely consistent among each of the respondent groups. As Table I indicates, upper management, first-level managers, and business faculty reported similar importance ratings for all of the factors except two - foundational systems and diagnostic efficiency.

Upper managers perceived foundational systems to be of less importance than first-level managers, and they perceived diagnostic efficiency to be of less importance

\begin{tabular}{lcccc}
\hline Factor & $\begin{array}{c}\text { Upper } \\
\text { managers } \\
(n=26)\end{array}$ & $\begin{array}{c}\text { First-level } \\
\text { managers } \\
(n=34)\end{array}$ & $\begin{array}{c}\text { Business } \\
\text { faculty } \\
(n=24)\end{array}$ & Total \\
\hline Knowledge factors & & & & \\
Project management & $4.41(4.23)$ & $4.56(4.32)$ & $4.48(4.52)$ & $4.49(4.35)^{*}$ \\
Requisite management & $4.10(4.00)$ & $4.09(3.99)$ & $4.14(4.22)$ & $4.11(4.06)$ \\
Materials management & $4.02(3.92)$ & $4.04(3.85)$ & $4.10(4.13)$ & $4.05(3.95)$ \\
Competitive strategies & $3.77(3.80)$ & $4.11(3.90)$ & $3.96(4.05)$ & $3.96(3.91)$ \\
Foundational systems & $3.45_{\mathrm{a}}(3.25)$ & $3.96_{\mathrm{b}}(3.60)$ & $3.87(3.74)$ & $3.78(3.53)^{*}$ \\
Skill factors & & & & \\
Organizational strategies & $4.44(4.19)$ & $4.32(4.27)$ & $4.53(4.53)$ & $4.42(4.32)$ \\
Transformational leadership & $4.24(4.12)$ & $4.32(4.25)$ & $4.13(4.15)$ & $4.24(4.18)$ \\
Workforce development & $4.21(4.05)$ & $4.27(4.18)$ & $4.21(4.13)$ & $4.23(4.13)$ \\
Technical analysis & $4.18(4.22)$ & $4.50(4.39)$ & $4.39(4.38)$ & $4.37(4.33)$ \\
Diagnostic efficiency & $3.47 \mathrm{a}(3.40)$ & $4.06 \mathrm{~b}(3.76)$ & $3.90 \mathrm{~b}(3.82)$ & $3.84(3.66)^{*}$ \\
Value factors & & & & \\
Credibility management & $4.64(4.51)$ & $4.67(4.55)$ & $4.58(4.59)$ & $4.63(4.55)$ \\
Collaborative management & $4.37(4.26)$ & $4.41(4.37)$ & $4.43(4.45)$ & $4.40(4.36)$ \\
Responsiveness management & $4.23(4.30)$ & $4.32(4.26)$ & $4.47(4.33)$ & $4.33(4.33)$ \\
Assertive leadership management & $3.89(3.79)$ & $4.11(4.00)$ & $3.78(3.68)$ & $3.95(3.84)^{*}$ \\
Notes Unique subscipts & & & & \\
& & & &
\end{tabular}

Notes: Unique subscripts indicate a significant difference (at the 0.05 level) between one group's mean versus the other (e.g. upper managers vs first-level managers). Means with the same subscript or with no subscript are statistically equivalent. * Indicates a significant difference between current and future importance

Table I.

Perceived current (future) importance of each factor 
than did the first-level managers and business faculty. One explanation for these differences is that upper management is somewhat removed from the day-to-day activities in MAMP operations and thus perceive the fundamental elements of these constructs to be of lesser importance than the first-level managers who are involved in the daily operations, and business faculty who teach the fundamental skills exemplified in the diagnostic efficiency construct. Another explanation is that from upper management's perspective, leadership and management-related competencies are more important management issues for the overall success of a firm than the functionally-specific competencies of foundational systems and diagnostic efficiency, which are presumably handled by production personnel themselves.

The consistency among the three panels regarding the relative importance of the 14 knowledge, skill, and value competencies provides evidence of the validity of these factors as important indicators of MAMP managerial competence. The initial list of competencies was generated by a panel of expert MAMP upper managers, and was cross-validated by a panel of first-level MAMP managers with firsthand, current experience in MAMP operations, and business management faculty who research the field and prepare future MAMP managers. While many of these competencies may be similar to those required by managers in any field, the specific set of competencies generated from this study are particularly suited for the unique challenges faced by those who manage MAMP operations.

\section{Higher-level factors}

The 14 knowledge, skill and value competencies are independent from one another to the extent that they represent the distinct educational objective classifications of knowledge, skills, and values. A second-order factor analysis was completed in order to examine meaningful competency overlaps across the three areas. Table II summarizes the results of this analysis.

Three higher-order factors emerged, which we named organizational leadership, responsiveness planning, and technical foundations. The organizational leadership scale is comprised entirely of skill and value competencies. The scale contains a high level of conceptual overlap focusing on the interpersonal side of leadership and management. The responsiveness planning construct focuses on the knowledge and skill competencies necessary to enable a manager to take action within the context of the organization's strategy and the competitive environment. The group that rates technical foundations high recognizes the importance of having technical knowledge and skills that allow them to make accurate diagnoses for efficient managerial decisions throughout the organization. Perhaps it is this construct that primarily differentiates the requisite competencies of an MAMP manager from non-technical managerial fields.

As in the case of the first-order factor analysis, a comparison of the relative importance of these higher-order factors across the respondent groups displays considerable consistency, with the exception of the technical foundations construct, which upper managers perceived to be of less importance than first-level managers (see Table III). 


\begin{tabular}{|c|c|c|c|c|c|c|}
\hline \multirow{2}{*}{\multicolumn{3}{|c|}{ Individual component scales }} & \multicolumn{3}{|c|}{ Component factor loadings } & \\
\hline & & & 1 & 2 & 3 & \\
\hline \multicolumn{7}{|c|}{ Organizational leadership $($ alpha $=0.86)$} \\
\hline VSCALE1 $\quad$ Credib & lity management & & 0.88 & 0.008 & 0.008 & \\
\hline SSCALE4 & rce development & & 0.78 & 0.23 & 0.11 & \\
\hline VSCALE3 & rative managemer & & 0.74 & 0.11 & 0.28 & \\
\hline SSCALE2 & ormational leaders & & 0.68 & 0.36 & 0.20 & \\
\hline VSCALE2 & ve leadership man & agement & 0.57 & 0.18 & 0.49 & \\
\hline \multicolumn{7}{|c|}{ Responsiveness planning $(a l p h a=0.81)$} \\
\hline KSCALE2 & itive strategies & & 0.001 & 0.78 & 0.33 & \\
\hline KSCALE5 & ls management & & 0.13 & 0.72 & 0.17 & \\
\hline KSCALE3 & siveness managen & ent & 0.57 & 0.67 & 0.03 & \\
\hline SSCALE1 & cal analysis & & 0.58 & 0.62 & 0.08 & \\
\hline SSCALE5 & zational strategies & & 0.44 & 0.46 & 0.003 & \\
\hline \multicolumn{7}{|c|}{ Technical foundations $($ alpha $=0.79)$} \\
\hline KSCALE1 & itional systems & & 0.07 & 0.12 & 0.90 & Table II. \\
\hline SSCALE3 & stic efficiency & & 0.23 & 0.29 & 0.81 & Second-order factor \\
\hline KSCALE4 & management & & 0.45 & 0.004 & 0.62 & analysis, factor loadings \\
\hline \multicolumn{3}{|c|}{ Requisite management } & 0.37 & 0.39 & 0.47 & and statistics \\
\hline Factor & Upper managers & First-lev & agers & Business faculty & Total & \\
\hline \multirow{3}{*}{$\begin{array}{l}\text { Organizational leadership } \\
\text { Responsiveness planning } \\
\text { Technical foundations }\end{array}$} & $4.27(4.14)$ & 4.36 & & $4.23(4.20)$ & $4.29(4.21)$ & \\
\hline & $4.13(4.09)$ & 4.26 & & $4.29(4.31)$ & $4.22(4.17)$ & \\
\hline & $3.86_{\mathrm{a}}(3.72)$ & 4.17 & & $4.10(4.07)$ & $4.05(3.90)^{*}$ & \\
\hline \multicolumn{6}{|c|}{$\begin{array}{l}\text { Notes: Unique subscripts indicate a significant difference (at the } 0.05 \text { level) between one group's mean } \\
\text { versus the other (e.g. upper managers vs first-level managers). Means with the same subscript or with } \\
\text { no subscript are statistically equivalent. * Indicates a significant difference between current and future } \\
\text { importance }\end{array}$} & $\begin{array}{r}\text { Table III. } \\
\text { Perceived current (future) } \\
\text { importance of } \\
\text { second-order factors }\end{array}$ \\
\hline
\end{tabular}

Future competency significance

A paired samples $t$-test was performed to compare the rating scores of the current agreement scales with the scores from the future significance scales (see Table I, numbers in parentheses). The difference in means between current and future importance was significant for four of the constructs: project management, foundational systems, diagnostic efficiency, and assertive leadership management. The same general trend was obtained for the other factors, but the means were not significantly different. One explanation for these results is the uncertainty of the future for MAMP managers. The panelists were confident in the importance of these competency factors for the current business environment, but exhibited greater uncertainty about the potential importance of these same factors in the future.

\section{Conclusions and recommendations}

In this study, we identified 14 competencies that define the scope of expertise required by successful MAMP managers. Some of these competencies, such as 
those labeled "competitive strategies", "project management", "transformational leadership", and "assertive leadership management", might be relevant for any managerial position. Others, however, such as "foundational systems", "materials management", and "diagnostic efficiency", incorporate competencies specifically within an MAMP context. It is within the knowledge and skill classifications that most of the competencies specific to MAMP seemed to emerge. Competencies relating to a manager's attitudes or values (credibility, assertive leadership, collaborative and responsiveness management) appear to be more universal across managerial domains.

The challenge for future research is to develop a competency model that identifies specific tasks and behaviors that manifest the competencies we have identified, describes the interrelationships among the competencies, and theorizes the antecedents and consequences of the competencies. Future research should also seek to refine the definitions of the constructs we have identified and the scales used to measure them. For managerial application, the competency model will also need to incorporate the MAMP organization's mission, strategy and culture. After development of a framework, the next step would be the examination of current practices against the proposed framework by training and development personnel.

The results of this study indicate that in order to be effective, MAMP managers must possess a unique balance of interpersonal and leadership skills that are commonly associated with managers in general, as well as a significant depth of technical knowledge and skills about engineering, design, manufacturing, and operations. The implications for this are twofold. First, it is not enough for management candidates to have technical knowledge about manufacturing; they must also possess knowledge, skills, and values corresponding to interpersonal leadership competencies. The study also suggests that candidates who have been successful managers outside the MAMP domain may not have the technical competencies necessary to manage the challenges in a manufacturing organization. The development challenge for MAMP managers will be integrating the organizational leadership competencies identified in this study along with the responsiveness planning and technical foundation competencies that are often already established in non-management positions. As technology and globalization continue to change the competitive landscape, organizations will increasingly rely on MAMP managers with the proper balance of technical and interpersonal leadership competencies to lead their firms.

\section{References}

Badawy, M.K. (1995), Developing Managerial Skills in Engineers and Scientists, Van Nostrand Reinhold, New York, NY.

D’Netto, B. and Sohal, A.S. (1999), “Changes in the production manager's job: past, present, and future trends", International Journal of Operations \& Production, Vol. 19 No. 2, pp. 157-81.

Hales, C. (1986), "What do managers do? A critical review of the evidence", Journal of Management Studies, Vol. 23 No. 1, pp. 88-115.

Hirsh, W. and Bevan, S. (1988), "What makes a manager?", Institute of Manpower Studies, report 144, Brighton, MI.

Howardell, D. (2003), "Creating the next generation workforce", APICS: The Performance Advantage, August, available at: www.theacagroup.com/nextgen.htm 
McKenna, S. (2002), "Can knowledge of the characteristics of 'high performers' be generalised?", The Journal of Management Development, Vol. 21 No. 9/10, pp. 680-702.

Parry, S.B. (1996), “The quest for competencies”, Training, July, pp. 48-56.

Rausch, E., Sherman, H. and Washbush, J.B. (2002), "Defining and assessing competencies for competency-based, outcome-focused management", The Journal of Management Development, Vol. 21 No. 3/4, pp. 184-201.

Rosenbaum, B.L. (1991), "Leading today's professional”, Research Technology Management, Vol. 34, pp. 30-8.

Whitely, R. (1989), "On the nature of managerial tasks and skills: their distinguishing characteristics and organisation”, Journal of Management Studies, Vol. 26 No. 3, pp. 209-24.

\section{Appendix. Individual scales and competencies}

Knowledge scales

KSCALE1 $=$ foundational systems $($ alph $a=0.83)$ :

- mechanical drawing (blue prints);

- manufacturing processes (machining welding);

- equipment control systems (plc's starters, etc.);

- properties of materials (metals plastics);

- pneumatic systems.

KSCALE2 = competitive strategies (alpha $=0.74)$ :

- product packaging;

- computer process simulation;

- customer relations;

- information technology management;

- marketing principles;

- product design and development;

- electronic commerce.

$K S C A L E 3=$ requisite management $($ alpha $=0.75)$ :

- regulatory compliance;

- ergonomics;

- risk management;

- industrial safety;

- facility layout and design;

- statistical process control.

KSCALE4 $=$ project management $($ alpha $=0.67)$ :

- project management;

- production scheduling;

- flexible manufacturing;

- process design (work flow);

- quality control. 
KSCALE5 $=$ materials management $(a l p h a=0.69)$ :

- enterprise resource planning;

- supply chain management;

- purchasing;

- material requirement planning;

- cost accounting (budgeting);

Skill scales

SSCALE1 = technical analysis $($ alpha $=0.81)$ :

- cost/benefit analysis;

- networking;

- written communication (technical);

- general computer literacy;

- forecasting;

- learning.

SSCALE2 = transformational leadership $($ alpha $=0.82)$ :

- negotiating;

- motivational strategies;

- multiple priority management;

- conflict resolution;

- interpersonal skills (human relations);

- benchmarking;

- mentoring/coaching;

- verbal communication (presentation);

- foreign languages.

SSCALE3 = diagnostic efficiency $($ alpha $=0.82)$ :

- mechanical trouble shooting;

- computer aided design and drafting;

- inspection;

- technical research;

- flow charting (control charting).

SSCALE4 $=$ workforce development $($ alph $a=0.71)$ :

- employee utilization;

- stress management;

- humor;

- taking ownership;

- diversity management.

SSCALE5 = organizational strategies $($ alpha $=0.61)$ :

- conceptual problem solving;

- crisis management; 
- customer awareness;

- critical thinking;

- team building/teamwork.

\section{Value scales}

VSCALE1 $=$ credibility management $($ alpha $=0.86)$ :

- responsible (consistent);

- self confidence;

- strong work ethic (diligent);

- common sense (objectivity);

- learning;

- ethical behavior (honesty);

- credibility (authentic);

- results-focused.

VSCALE2 = assertive leadership management $($ alpha $=0.78)$ :

- achievement orientation (competitive);

- confronting;

- charismatic;

- question authority;

- risk-taking;

- company loyalty (profitability);

- ambitious (initiative).

VSCALE3 = collaborative management $($ alpha $=0.77)$ :

- empathy (fairness, approachable);

- team player;

- patience;

- willingness to get one's hands dirty;

- humility;

- customer oriented;

- love what you do (passion, enthusiasm).

VSCALE4 $=$ responsiveness management $($ alph $a=0.70)$ :

- future vision;

- comfortable in ambiguity;

- good listener;

- adaptable to change. 